\title{
GLOBAL TRENDS AND PROSPECTS IN POLYURETHANE BASED COMPOSITE WITH CARBON FIBER: A BIBLIOMETRIC ANALYSIS
}

\author{
Kumar Anubhav, Upinder Pal Singh \\ E-Mail Id: kumar.anubhav71@gmail.com, drupslko@gmail.com \\ Central Institute of Petrochemicals Engineering \& Technology, Lucknow, Uttar Pradesh, India
}

FEATURES

$>$ Polyurethane-based composite with carbon fibre (PUCFs) their historical date and research status are summarized.

$>$ By using bibliometrics analysis- providing Quantitative and Qualitative evidence.

$>$ PCFs research is reviewed based on their geographical distribution and published sources.

$>$ PUCFs research Challenges and their prospects are reviewed.

Abstract-Polyurethane (PU) is the most versatile group of Polymer materials \& carbon fiber is the best appropriate reinforcing material. Quantitative and Qualitative evidence from bibliometrics is used for in-depth statistical analysis which provides research knowledge and also presents research progress along with new trends in the particular research area. For Bibliometric analysis, we use the time frame from its inception to April 13, 2021 , search \& collect the data from the Web of Science (WoS) database platform. In our analysis, it shows that there is a significant increase in research paper number from 2014 onwards. Worldwide, most research came from China and India came on 5th position with only 12 articles were china with 125 articles. Moreover, in this study, we systematically elaborated the hotspots of PUCFs studies. Towards the end, we analyze some topics and perspectives that indicate current scientific hotspots and also try to bring insights for future research directions. Keywords: Polyurethane, carbon fiber, composite, Bibliometric analysis.

\section{INTRODUCTION}

Polyurethane (PU) is the most versatile group of Polymeric materials and it was first described by Bayer in 1937. It is available in two forms Thermoplastic \& Thermoset. PU is being formed from two raw materials (Resin \& Hardener). It is commonly formed by reacting a di- or triisocyanate with a polyol. Depending on its processing condition, it will have multiple industrial applications. It possesses a strong aspect of sustainability mainly due to its excellent properties. Several forms of PU are being produced \& used in our day-to-day life i.e sheets, foams, adhesives, etc. It can tailor to be either flexible or rigid according to our requirements. Mainly two downsides for PU have susceptibility towards is discoloration (yellow) tendency of aromatic urethanes when exposed to UV light \& secondly their susceptibility to microbiological attack. [1]

Typically, we will be found PU uses in several places i.e couches, insulation, liquid coatings and paints, mattresses, soft flexible foam toys, some elastic fibers. Only One constrain for PU is its low melting temperature $\left(130^{\circ} \mathrm{C}\right)$ but the cost is comparatively low with another one with similar properties. If we compare the flexibility \& mechanical properties of Silicon, Polyurethane \& epoxy, we will be found that Polyurethane lies between Silicon \& Epoxy. But if we consider temperature resistance as a parameter, Polyurethane lies after silicones \& epoxy. [2]

To enhance the properties of PU composite, we incorporate a wide range of reinforcement i.e Natural fiber, Carbon fiber (CFs), etc. Here we are using carbon fiber as a reinforcement \& PU as a matrix. As we discussed here, using carbon fiber as a reinforcement, is mainly due to its high-temperature resistance, excellent mechanical properties, and chemical stability. In Carbon fibers, Carbon atoms are bonded together to form along chain \& they come up in 5-10 micrometers diameter. Carbon fiber is mainly produced from Polyacrylonitrile (PAN). Almost $90 \%$ of carbon fiber is PAN Based. Rest is produced from rayon or petroleum pitch. Carbon fibers have several applications in Automobile \& Aircraft industry, Sports Industry \& Power plant field due to their high tensile strength, low weight $\&$ high stiffness. It is produced into several forms' uni-directional, weaves, braids, yarns, etc. Carbon fiber possesses similar properties as steel and its weight is also around the same as plastic. Based on precursor fiber materials, properties, and final heat treatment temperature carbon fibers are classified. [3] For determining the properties of the composite, interfacial bonding is very highly important in determining it. Carbon fiber surface is inert as well as smooth, which turns in low interfacial bonding with PU. So, we modify the surface of carbon fiber \& it is done by several methods i.e plasma treatment, polymer sizing, oxidation treatment, surface grafting, etc. But the best practice in surface modification is air oxidation due to its low cost \& easy operation. [4] In the current scenario, Bibliometric analysis is used as a tool to identify published records and it is widely accepted as an alternative method to evaluate the academically detailed topics in the library. It also helps to predict the new research trends \& provide a researcher a new idea for future research. In this study, we created social network maps through the review and analysis of the number, trends, research, and citation frequency. [5] 
ICAASET-2021, 20-21 May, 2021, K.R. Mangalam University, Gurugram

International Journal of Technical Research \& Science (Special Issue) ISSN No.:2454-2024 (online)

\section{METHODOLOGY}

\subsection{Search criteria \& data source for Analysis}

In our study, I thoroughly searched the Web of Science database from its beginning to April 13, 2021, by using the following terms "Carbon fiber" and "Polyurethane". My focus is primarily based on to finding combined (Carbon fiber \& Polyurethane) research papers.
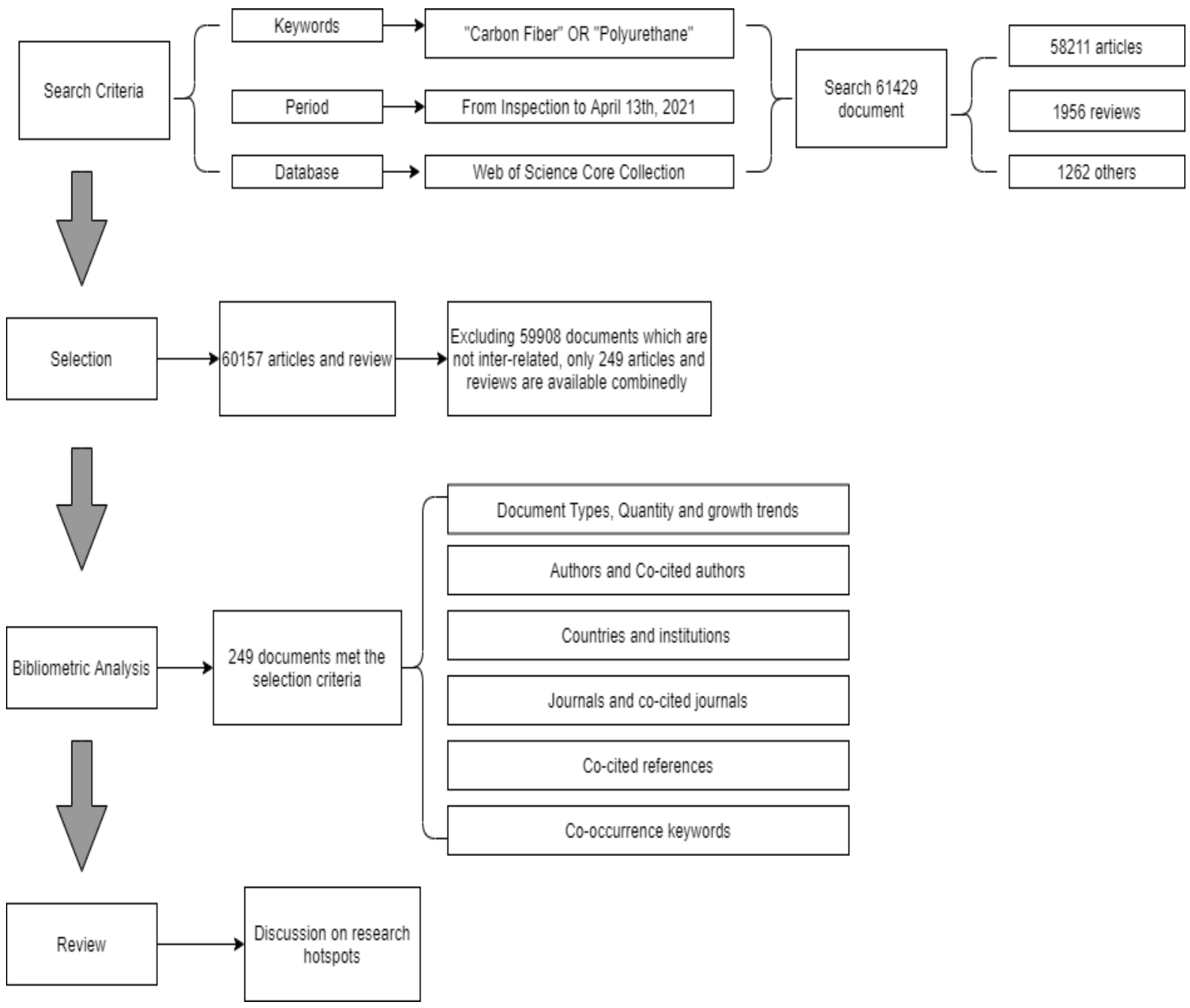

Fig. 2.1 Selection of Papers and flow chart for research framework (Source: Author's work) Our focus is primarily based on finding combined (Carbon fiber \& Polyurethane) research papers. No restriction was imposed on language, document type, data category, geographical scrutiny, Affiliations, or document year. During preliminary selection, I study the title \& abstract of the paper \& I excluded those topics which are alone $\&$ not in combined form. In fig. 1, We demonstrated the study selection and flow chart of the research framework.

\subsection{Analysis Method}

For forming social network maps, we used RStudio software to analyze the document type, years, authors, cocited authors, countries, institutions, journal sources, co-cited journals, keywords, and co-cited references. Data aggregation and its analysis were conducted with the help of the biblioshiny tool \& Microsoft Excel whereas, for the flow chart, we used Draw.io. Journals, authors, or references cited together by researcher care called as cocited [6]. While searching the countries that authors of the published records significantly came from China alone. Social network analysis (SNA) is the main method used for the analysis of co-occurrence [7]. Research hotspots and trends of PUCFs research are reflected by bibliometrics methods \& it has the function of multidimensional information display. With the help of social network maps, it helps to indicate importance with the size of a node and the thickness of a line [8]. The number of frequencies is represented by the node \& associations refer to the lines between the nodes. For greater the relationship, the line should be thicker [9]. So, the trends in PUCFs research will be visualized by using the resulting co-worked network.

\section{RESULTS}

\subsection{Paper Type and quantity}

Total 61429 Articles and review papers are identified based on my selection criteria "Carbon Fiber" AND "Polyurethane". Statistical data are sorted and analyzed which include studies and draw a preliminary conclusion. Identified paper based on sorting are classified into 6 types (Fig. 3.1) 
ICAASET-2021, 20-21 May, 2021, K.R. Mangalam University, Gurugram

International Journal of Technical Research \& Science (Special Issue) ISSN No.:2454-2024 (online)

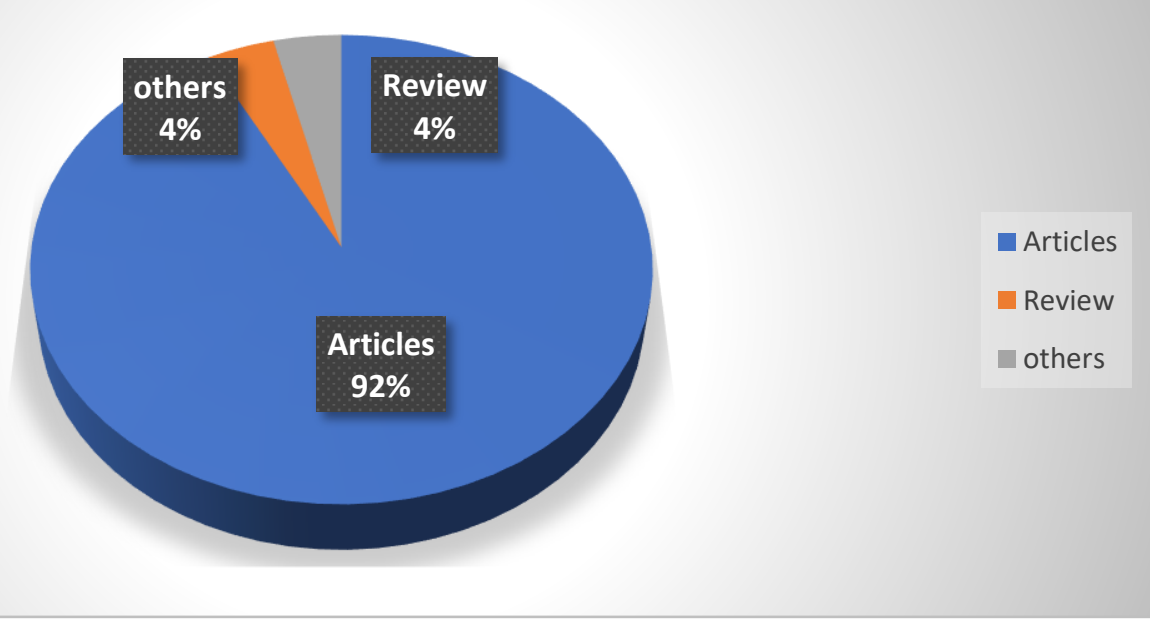

Fig. 3.1 Document type percentage of reports for PUCFs research (Data Source: WoS)

Articles with $92 \%$ stacks followed by $4 \%$ review \& $4 \%$ others. Here we have observed that the no of articles \& reviews is the highest that reflects the development trends and change in PUCFs research. So, we focused on these two types of papers for further analysis and evaluation. Total 249 papers are analyzed.

The number of papers slowly increased, with not more than 7 papers per year before 2015. But the number of papers has increased significantly year by year in the combined research field of Carbon fibers \& Polyurethane. In 2019 total of 47 papers published followed by 52 in the year 2020 .

\subsection{Active authors, countries, institutions, Most relevant source, So on}

Total 958 authors were involved in the combined research field of Carbon fibers \& Polyurethane. In Table 3.1, top ten relevant sources. In which "JOURNAL OF APPLIED POLYMER SCIENCE" is the most relevant one with 14 articles.

Table-3.1 Most relevant source

\begin{tabular}{|c|c|}
\hline Sources & Articles \\
\hline JOURNAL OF APPLIED POLYMER SCIENCE & 14 \\
\hline COMPOSITES PART B-ENGINEERING & 9 \\
\hline COMPOSITES SCIENCE AND TECHNOLOGY & 9 \\
\hline COMPOSITE STRUCTURES & 7 \\
\hline COMPOSITES PART A-APPLIED SCIENCE AND MANUFACTURING & 7 \\
\hline JOURNAL OF COMPOSITE MATERIALS & 6 \\
\hline JOURNAL OF REINFORCED PLASTICS AND COMPOSITES & 6 \\
\hline MATERIALS TRANSACTIONS & 5 \\
\hline POLYMER COMPOSITES & 5 \\
\hline SMART MATERIALS AND STRUCTURES & 5 \\
\hline
\end{tabular}

China with the largest number of articles present in this field is $128 \&$ then in 2nd position is with the USA with 18 articles, India is on 5th with only 12 articles. It shows that in our country lots of research works are required in this field to fill the gap. Total 30 countries contributed to the PUCFs research field. These data are illustrated below:

Table-3.2 Countries production against articles till $13^{\text {th }}$ April 2021

\begin{tabular}{|l|r|r|r|r|r|}
\hline Country & \multicolumn{1}{|l|}{ Articles } & \multicolumn{1}{l}{ Freq } & \multicolumn{1}{l}{ SCP } & MCP & MCP_Ratio \\
\hline CHINA & 128 & 0.51613 & 114 & 14 & 0.1094 \\
\hline USA & 18 & 0.07258 & 12 & 6 & 0.3333 \\
\hline JAPAN & 13 & 0.05242 & 11 & 2 & 0.1538 \\
\hline KOREA & 13 & 0.05242 & 12 & 1 & 0.0769 \\
\hline INDIA & 12 & 0.04839 & 11 & 1 & 0.0833 \\
\hline TURKEY & 9 & 0.03629 & 8 & 1 & 0.1111 \\
\hline SPAIN & 8 & 0.03226 & 8 & 0 & 0 \\
\hline GERMANY & 7 & 0.02823 & 5 & 2 & 0.2857 \\
\hline
\end{tabular}


ICAASET-2021, 20-21 May, 2021, K.R. Mangalam University, Gurugram

International Journal of Technical Research \& Science (Special Issue) ISSN No.:2454-2024 (online)

Among Various countries was very close in cooperation, in which China has the most frequent exchanges with Japan \& Singapore. Harbin Institute of Technology, China is established in 1920 \& it is the most relevant institution, who contributed to the research of PUCFs \& from here total 18 no of articles were produced.

Table-3.3 Most Relevant institutions with no of articles they produced

\begin{tabular}{|c|c|c|c|}
\hline Affiliations & Articles & Affiliations & Articles \\
\hline HARBIN INST TECHNOL & 18 & SICHUAN UNIV & 8 \\
\hline DONGHUA UNIV & 15 & BEIJING UNIV CHEM TECHNOL & 7 \\
\hline TOKAI UNIV & 13 & INST COAL CHEM & 7 \\
\hline SHINSHU UNIV & 11 & UNIV CHINESE ACAD SCI & 7 \\
\hline FENG CHIA UNIV & 10 & XI AN JIAO TONG UNIV & 7 \\
\hline
\end{tabular}

From bibliometrics analysis, we came to know about the Top-Authors who published their articles over time. Yu Liu is a prominent author in the field of PUCFs, he contributed to this research area since 2016. Qing-Qing Ni is the most consistent authors in this field since 2009. Refer to Fig. 3.2 for the Top-Authors who contributed to the research of PUCFs.

\section{Top-Authors' Production over the Time}

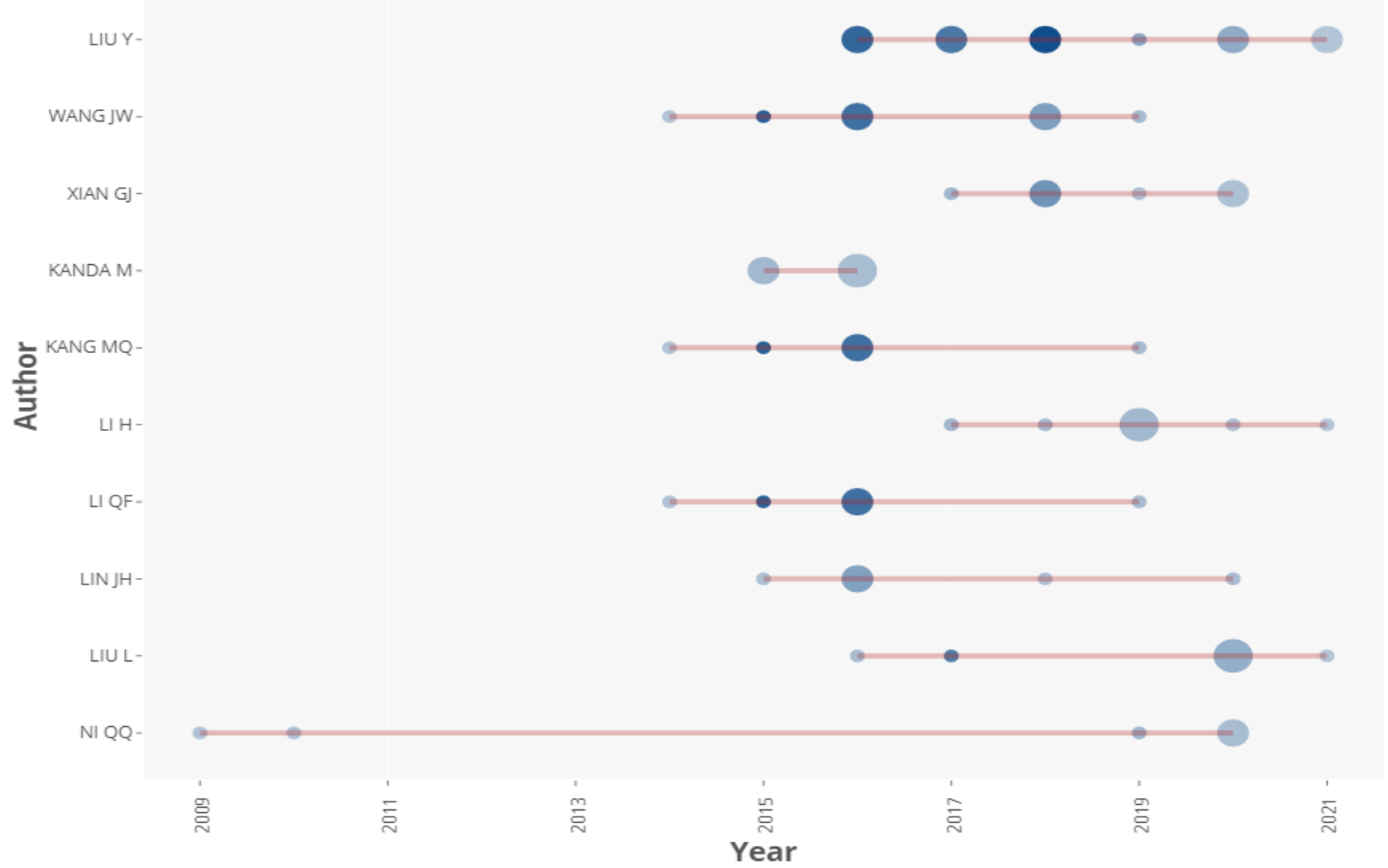

Fig. 3.2 Top-Author's Production Over the time (Source: WoS Database and figure generated from biblioshiny)

From Table 3.4, we concluded that China positioned No 1 in the total citation, but average article citations were lower than USA, Singapore, or Germany. Refer to Table 3.4 for more details.

Table-3.4 Most Relevant institutions with no of articles they produced

\begin{tabular}{|c|c|c|}
\hline Country & Total Citations & Average Article Citations \\
\hline CHINA & 1728 & 13.50 \\
\hline USA & 540 & 30.00 \\
\hline SINGAPORE & 435 & 435.00 \\
\hline JAPAN & 149 & 11.46 \\
\hline GERMANY & 140 & 20.00 \\
\hline KOREA & 104 & 8.00 \\
\hline UKRAINE & 93 & 93.00 \\
\hline IRAN & 79 & 39.50 \\
\hline TURKEY & 73 & 8.11 \\
\hline IRELAND & 70 & 70.00 \\
\hline
\end{tabular}


ICAASET-2021, 20-21 May, 2021, K.R. Mangalam University, Gurugram

International Journal of Technical Research \& Science (Special Issue) ISSN No.:2454-2024 (online)

Hua Zhang from Nanyang Technological University published a paper in 2016, which is the most cited article around the Globe. Refer to Table 3.5 for the most cited document around the Globe.

Table-3.5 Most cited article around the Globe

\begin{tabular}{|l|l|r|r|r|}
\hline \multicolumn{1}{|c|}{ Paper } & \multicolumn{1}{|c|}{ DOI } & \multicolumn{1}{c|}{$\begin{array}{c}\text { Total } \\
\text { Citations }\end{array}$} & \multicolumn{1}{c|}{$\begin{array}{c}\text { TC per } \\
\text { Year }\end{array}$} & \multicolumn{1}{c|}{$\begin{array}{c}\text { Normalized } \\
\text { TC }\end{array}$} \\
\hline MA QL, 2016, SMALL & $10.1002 /$ smll.201503685 & 435 & 72.5 & 12.6755 \\
\hline $\begin{array}{l}\text { GUNES IS, 2008, } \\
\text { POLYMER }\end{array}$ & $10.1016 /$ j.polymer.2008.03.021 & 182 & 13 & 2.5877 \\
\hline $\begin{array}{l}\text { MADBOULY SA, 2010, } \\
\text { ADV POLYM SCI }\end{array}$ & $10.1007 / 12 \_2009 \_28$ & 100 & 8.3333 & 2.439 \\
\hline $\begin{array}{l}\text { HU Z, 2018, } \\
\text { NANOTECHNOLOGY }\end{array}$ & $10.1088 / 1361-6528 /$ aab010 & 99 & 24.75 & 6.5501 \\
\hline $\begin{array}{l}\text { JIANG S, 2015, COMPOS } \\
\text { SCI TECHNOL }\end{array}$ & $10.1016 /$ j.compscitech.2015.01.022 & 94 & 13.4286 & 3.514 \\
\hline $\begin{array}{l}\text { SCHUVAILO OM, 2006, } \\
\text { ANAL CHIM ACTA }\end{array}$ & $10.1016 /$ j.aca.2006.03.034 & 93 & 5.8125 & 3.8219 \\
\hline $\begin{array}{l}\text { KISHI H, 2004, COMPOS } \\
\text { SCI TECHNOL }\end{array}$ & $10.1016 /$ j.compscitech.2004.05.006 & 83 & 4.6111 & 1.7382 \\
\hline $\begin{array}{l}\text { WANG TM, 2010, MATER } \\
\text { DESIGN }\end{array}$ & $10.1016 /$ j.matdes.2010.03.029 & 80 & 6.6667 & 1.9512 \\
\hline $\begin{array}{l}\text { BAJWA DS, 2019, IND } \\
\text { CROP PROD }\end{array}$ & $10.1016 /$ j.indcrop.2019.111526 & 73 & 24.3333 & 8.1316 \\
\hline $\begin{array}{l}\text { CULEBRAS M, 2018, ACS } \\
\text { SUSTAIN CHEM ENG }\end{array}$ & $10.1021 /$ acssuschemeng.8b01170 & 70 & 17.5 & 4.6314 \\
\hline
\end{tabular}

While analyzing word cloud around the articles, we concluded, in most articles "mechanical Properties" are the most prominent word followed by behavior, performance, and so on. In Fig 3, we are showing the Word Cloud which frequently occurred in the articles. Mechanical Properties occurs by $9 \%$, performance by $6 \%$, strength by $5 \%$, and so on.

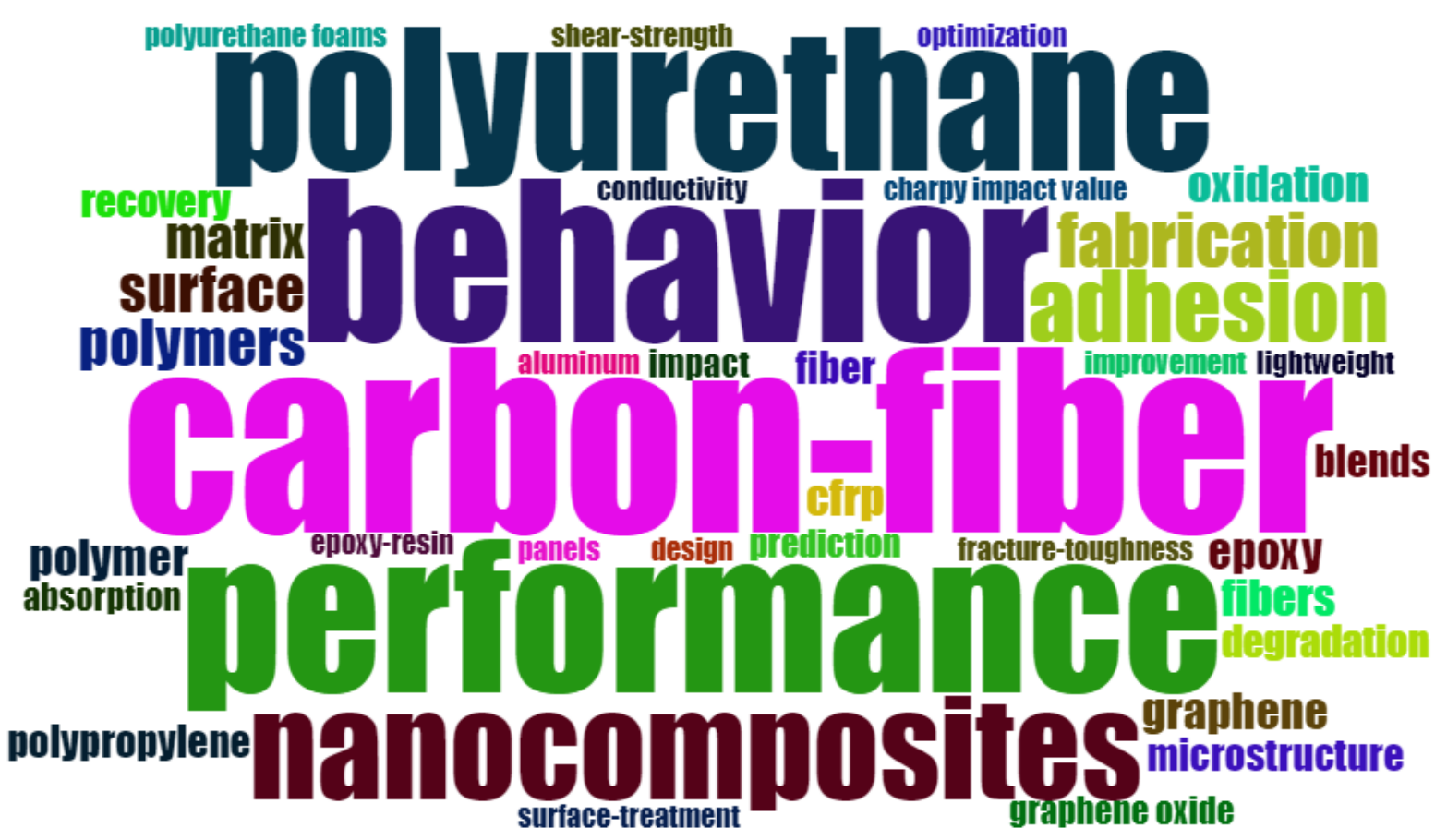

Fig. 3.3 Word Cloud (Source: WoS Database and figure generated from biblioshiny)

\section{RESEARCH ARTICLES ANALYSIS}

In our Analysis, we reviewed top ten most globally cited articles.

$>$ In the aquatic environment, there is a catastrophic impact due to Oil Spill accidents. Special wettable material is used to separate oil and water. These wettable materials are based on filtration \& absorption techniques. CNT-based 3D absorbents provide better results in removing oil from water but due to their expensive precursors and complex preparation process, it not practically viable to use. So, it is important to explore another carbon-based precursor, those that have low cost and ease in processing i.e Twisted carbon fiber aerogels preparation by pyrolysis raw cotton directly. Hereafter pyrolysis fibrous structure of cotton is maintained but more twisted carbon fibers are 
obtained. Whereas PU-based Sponges are used mostly because they are economical, better elasticity $\&$ their fabrication is on an industrial scale. One drawback with absorbents is while separating oil $\&$ water, they have limited absorption capacity. Future research direction suggested that to study the interaction of the wettable surface with oil \& water mixture, tailored the properties of a material to switchable wetting properties \& find the most viable method of preparation which will suit for industry. [10]

$>$ Evaluation \& effect of Shape memory properties for Polyurethane by nano-size filler, they may be carbon black, carbon nanofibers, silicon carbide or organoclay, etc. Preparation of composite by melt mixing. By heating the test piece above the melting point, it triggers the behavior of shape memory of the composite. Beyond certain loading, shape memory properties destroy by carbon black. For better shape memory with organoclay, organoclay positively contributes to mechanical reinforcement without interfering with the crystallinity of the soft segment. By the presence of these fillers i.e carbon nanofiber and silicon carbide, significantly reduces the extent of crystallinity \& crystallization temperature. Data from cyclic tensile testing shows fillers didn't impart any effect on shape memory polyurethane nanocomposite. [11]

$>$ The Composite having shape memory properties, it enables them not only for recovery from highstress levels but it contributes to its bio functionality magnetism and electrical conductivity. Enhancement of mechanical properties of shape memory polymer by the help of fillers i.e layered silicates, Polyhedral Oligomeric Silsesquioxanes (POSS). Incorporation of Fillers to polymer also leads to enhancement of its modulus, strength, lowered gas permeability, heat resistance \& flame retardancy. Interfacial interaction between polymer matrix and fillers leads to the enhancement of mechanical properties \& it help to create novel functions. From fiber-filled composite, we will achieve Anisotropic properties. Effect on properties is different by nanosized filler to macro size filler. The size \& geometry classified the fillers. [12]

$>$ The detection \& repair of interfacial microcracks is difficult in resin matrix composite. Single poly(p-phenylene benzobisoxazole) (PBO) composite is prepared by using thermoplastic polyurethane as a matrix. PBO is applied as reinforcement in the composite. Interfacial damage has occurred, when a single fiber pulls out but is self-healed by Xe light irradiation. capsule-based methods, microvascular networks are such method which is used to prepare self-healing material. In this study, Ag-Cu2S-PBO fibers are fabricated with light-triggered self-healing property. [13]

$>$ Fabrication of Polyurethane based composite with carbon fibers has major problems regarding lack of interfacial bonding. Surface salination is one process that will improve the interfacial bonding between them. By using X-ray photoelectron spectroscopy, we examine the change in surface composition of carbon fibers. By using scanning electron microscopy (SEM), we analyzed the morphology \& fracture surface of the composite. By grafting silane molecule on the carbon fiber surface in the form of uniform polysiloxane coating, it improves the mechanical properties as well as interfacial shear strength, which results in an increase of $18.3 \%$ in tensile strength. [14]

$>$ An alternative method for the production of amperometric micro biosensors is executed by combining electrochemical electrometallization and electropolymerization of phenylene diamine film with covalent binding enzymes. For highly selective detection of hydrogen peroxide in the presence of a different kind of interfering compounds i.e uric acid, ascorbic acid, etc. on the top of the ruthenium layer, a semi-permeable polymer film is developed on it with the help of electropolymerization of m-phenylene diamine. By cross-linking the enzymes with BSA by glutaraldehyde is done, while ascorbate oxidase is present. Top of the enzymatic membrane, the additional layer of polyurethane and Nafion is deposited which helps to improve the dynamic range of the biosensor by $4 \mathrm{mM}$ for glucose, $1.75 \mathrm{mM}$ for lactate, and $0.25 \mathrm{mM}$ for glutamate. These micro biosensors are used by Vivo. [15]

$>$ In carbon fiber reinforced plastic, epoxy is used as resin, which enhances the heat resistance as well as modulus. But rigid epoxy resins lower the crack resistance, which became its major drawback. So, to rectify these problems elastomers are incorporated into thermoplastic blends to enhance the crack resistance of the composite. But beyond a certain limit, it won't necessarily improve the impact resistance of the composite. So, incorporate toughened interlaminar layer into the composite which suppresses the interlaminar damage. To eliminate the vibration \& noise of composite parts, and interleaving approach is used. For interleaving material, thermoplastic elastomeric films are used i.e polyamide elastomers, polyurethane elastomers, or polyethylene-based ionomers. Interleaved polymer films having viscoelastic properties, which showed damping properties of corresponding laminates. For controlling the loss factor of laminates, at the resonating frequency, the stiffness of films plays an important parameter. [16]

$>$ Polyurethane and epoxy resin composite is prepared by grafting an interpenetrating polymer network. Whereas interpenetrating polymer network is a polymer alloy in which two or more polymers formed a network, in which they hold together by occasional covalent bonds between those polymers' chains. Interpenetrating polymer network composites have excellent thermal as well as mechanical properties as compared to single component for improving damping properties $\&$ thermal decomposition of Polyurethane and epoxy resin composite, we should incorporate short carbon fibers and micro hollow glass beads. Carbon fibers having high tensile strength, thermal 
conductivity, and young's modules at the other end micro hollow glass beads having low density, sound insulation, and also heat resistance. In this study, we concluded that by adding $5 \%$ of carbon fibers by weight adding in the interpenetrating polymer network, it shoes best damping properties. Again, we add micro hollow glass beads $3 \%$ by weight into the carbon-filled composite, damping properties improve further. So, we can use short carbon fibers and micro hollow glass beads in damping structural materials for better results. [17]

$>$ Lignin is an organic material \& the second most abundant material in nature. From waste material generated in the production of paper and ethanol, we can extract Lignin. There are two main categories found in Lignin, they are ligno-sulphonate and kraft lignins. ligno-sulphonate holds around $88 \%$ stacks in total lignin whereas kraft lignins only $9 \% \&$ organosolv by $2 \%$. We are expecting high growth in the segment of organosolv mainly because of the focus on the production of biofuels. the compound annual growth rate of organosolv will be around $5 \%$ by 2025 . Chemical lignin is a polyaromatic polymer. Lignin is burnt to use as fuel for power and heat. By lignin valorization, we can obtain many viable product i.e fuels, chemicals \& other material. [18]

$>$ Most carbon fibers are derived from polyacrylonitrile (PAN) but the cost is high. We can consider lignin as a green alternative for the production of carbon fibers. Lignin is amorphous. The production of carbon fibers by using lignin as a precursor is a challenging task because of its brittleness and also has limited thermoplastic nature. To remove these drawbacks of lignin, chemical modification is done to impart thermoplastic nature $\&$ increase ductility. To overcome these drawbacks, we produce a blend of biopolymer by using hydroxypropyl modified Kraft hardwood, Alcell organosolv hardwood lignin, and thermoplastic polyurethane. When the sample contains more than $30 \%$ of thermoplastic polyurethane, we get excellent carbonization yield and melt processability. [19]

In reference to above mentioned top ten articles review, researchers claim that this area of research is growing and there is a need for further study with special reference to composite. We can fabricate composite according to our requirement

\section{CONCLUSION AND SCOPE FOR FUTURE RESEARCH}

From this bibliometrics analysis, PUCFs composite is unexplored the way it requires. So, it leads us to fabricate a composite by using carbon fiber fabric \& flexible polyurethane \& hoping it will be utilized for High-Altitude clothing for Defence Personnel in rough terrain. In our further study, we are going to evaluate the morphological properties of composite by scanning electron microscope, dart impact test for damping properties of the composite, and for the surface functional group we using Fourier-transform infrared spectroscopy. For Future research direction, we can also fabricate composite by using the non-foaming grade of polyurethane with short \& long carbon fibers \& examine the enhanced properties. The non-foaming grade of Polyurethane is used as a potting compound in electronic assembly, Photovoltaic potting, and so on. Lots of work has been already done in the fabrication of composite by rigid polyurethane \& carbon fiber, but for flexible polyurethane \& non-foaming polyurethane, still needs a lot to explore.

\section{REFERENCES}

[1] "POLYURETHANES," Chemical Retrieval on the Web (CROW), 2021. [Online]. Available: https://polymerdatabase.com/polymer\%20classes/Polyurethane\%20type.html. [Accessed 1442021 ].

[2] "Potting Compounds," Henkel Adhesive Technologies, 2021. [Online]. Available: https://www.henkeladhesives.com/in/en/products/potting-encapsulating-injection-molding-compounds/pottingcompounds.html. [Accessed 144 2021].

[3] P. Bhatt and A. Goel, "Carbon Fibres: Production, Properties and Potential Use," Material Science Research India, vol. 14, no. 1, pp. 52-57, 2017.

[4] R. Ma, W. Li, M. Huang, X. Liu and M. Feng, "Enhancing strength and toughness of carbon fibers reinforced rigid polyurethane," Polymer Testing, vol. 71, pp. 156-162, 2018.

[5] Y. Zhang, S. Pu, X. Lv, Y. Gao and L. Ge, "Global trends and prospects in microplastics research: A bibliometric," Journal of Hazardous Materials, vol. 400, 2020.

[6] C. Yang, X. Wang, X. Tang, X. Bao and R. Wang, "Research trends of stem cells in ischemic stroke from 1999 to 2018: A bibliometric analysis," Clinical Neurology and Neurosurgery, vol. 192, 2020.

[7] G. Mao, N. Huang, L. Chen and H. Wang, "Research on biomass energy and environment from the past to the future: A bibliometric analysis," Sci Total Environ, vol. 635, pp. 1081-1090, 2018.

[8] F. Padilla, M. Gallardo and F. Manzano-Agugliaro, "Global trends in nitrate leaching research in the 19602017 period," Sci Total Environ, vol. 643, pp. 400-413, 2018.

[9] Y. Gao, L. Ge, S. Shi and Y. Sun, "Global trends and future prospects of e-waste research: a bibliometric analysis," Environmental Science and Pollution Research, vol. 26, 2019.

[10] Q. Ma, H. Cheng, A. G. Fane , R. Wang and . H. Zhang, "Recent Development of Advanced Materials with Special Wettability for Selective Oil/Water Separation," Small. 12. 2186-2202. 10.1002/smll.201503685., vol. 12, no. 16, pp. 2186-2202, 2016. 
ICAASET-2021, 20-21 May, 2021, K.R. Mangalam University, Gurugram

International Journal of Technical Research \& Science (Special Issue) ISSN No.:2454-2024 (online)

[11] I. S. Gunes, F. Cao and S. C. Jana, "Evaluation of nanoparticulate fillers for development of shape memory polyurethane nanocomposites," Polymer, vol. 49, no. 9, pp. 2223-2234, 2008.

[12] S. A. Madbouly and A. Lendlein, "Shape-Memory Polymer Composites," Advances in Polymer Science, vol. 226, pp. 41-95, 2010.

[13] Z. Hu, Q. Shao, Y. Huang, L. Yu, D. Zhang, X. Xu, J. Lin, H. Liu and Z. Guo, "Light triggered interfacial damage self-healing of poly(p- phenylene benzobisoxazole) fiber composites," Nanotechnology, vol. 29, no. 18, 2018.

[14] S. Jiang, Q. Li, Y. Zhao, J. Wang and M. Kang, "Effect of Surface Silanization of Carbon Fiber on Mechanical Properties of Carbon Fiber Reinforced Polyurethane Composites," Composites Science and Technology, vol. 110, pp. 87-94, 2015.

[15] O. M. Schuvailo, O. O. Soldatkin, A. Lefebvre, R. Cespuglio and A. P. Soldatkin, "Highly selective microbiosensors for in vivo measurement of glucose, lactate and glutamate," Analytica Chimica Acta, Vols. 573-574, pp. 110-116, 2006.

[16] H. Kishi, M. Kuwata, S. Matsuda, T. Asami and A. Murakami, "Damping properties of thermoplasticelastomer interleaved carbon fiber-reinforced epoxy composites," Composites Science and Technology, vol. 64, no. 16, pp. 2517-2523, 2004.

[17] T. Wang, S. Chen, Q. Wang and X. Pei, "Damping analysis of polyurethane/epoxy graft interpenetrating polymer network composites filled with short carbon fiber and micro hollow glass bead," Materials \& Design, vol. 31, no. 8, pp. 3810-3815, 2010.

[18] D. Bajwa, G. Pourhashem, A. Ullah and S. Bajwa, "A concise review of current lignin production, applications, products and their environmental impact," Industrial Crops and Products, vol. 139, 2019.

[19] M. Culebras, A. Beaucamp, Y. Wang and M. M. Clauss, "Biobased Structurally Compatible Polymer Blends Based on Lignin and Thermoplastic Elastomer Polyurethane as Carbon Fiber Precursors," ACS Sustainable Chemistry \& Engineering, vol. 6, no. 7, pp. 8816-8825, 2018. 